\title{
Meningioma fibroblástico em bovino no semiárido da Paraíba
}

\author{
Fibroblastic meningioma in cattle in semi-arid of Paraiba, Brazil
}

\author{
Fabricio Kleber de Lucena Carvalho ${ }^{{ }^{*}}$ Antônio Flávio Medeiros Dantas ${ }^{\mathrm{I}}$ \\ Andrei Manoel Brum Febrônio ${ }^{\text {II }}$ Franklin Riet-Correa ${ }^{\mathrm{I}}$ Glaucia Denise Kommers ${ }^{\mathrm{III}}$ \\ Sara Vilar Dantas Simões ${ }^{\mathrm{I}}$
}

\begin{abstract}
Descreve-se um caso de meningioma fibroblástico em bovino no semiárido da Paraíba. O animal apresentava depressão, descarga nasal purulenta, bruxismo, ptose da pálpebra, flacidez da língua e trismo. Na necropsia, havia uma massa tumoral na região do córtex frontal direito, que ocupava o ventrículo lateral direito. Microscopicamente, era formado por células meningoteliais neoplásicas. O diagnóstico foi realizado pelas características histológicas e confirmado pela imuno-histoquímica, que revelou marcação positiva para vimentina e negativa para citoqueratina, proteína ácida fibrilar glial e enolase neuro-específica. As neoplasias do sistema nervoso central, diagnosticadas em bovinos no semiárido do nordeste brasileiro, embora raras, devem ser incluídas no diagnóstico diferencial das doenças de bovinos que apresentam sinais nervosos.
\end{abstract}

Palavras-chave: ruminantes, neoplasia, sistema nervoso central.

\section{ABSTRACT}

A case of fibroblastic meningioma is reported in a bovine, presenting depression, purulent nasal discharge, bruxism, eyelid ptosis, tongue paralysis, and trismus. At necropsy there was a tumor in the region of the right frontal cortex, occupying the right lateral ventricle. Microscopically it was composed by neoplastic meningothelial cells. The diagnosis was performed based on histologic characteristics and confirmed by immunohistochemistry revealing that tumor cells were positive for vimentin and negative to cytokeratin, glial fibrillary acidic protein, and neuron specific enolase. Diseases of the central nervous system are important in cattle in the semiarid region of northeastern Brazil, and tumors of the brain and spinal cord should be included in the differential diagnosis of this group of diseases.

Key words: ruminants, neoplasia, central nervous system.
Meningiomas são tumores primários do sistema nervoso central (SNC) comuns em humanos e raros em bovinos. Eles são derivados das células meningoteliais da aracnoide e pia-máter, mais frequentemente observados no encéfalo do que na medula espinhal (KOESTNER \& HIGGINS, 2002).

A ocorrência de tumores do SNC em bovinos é pouco relatada no Brasil. Em estudos retrospectivos de neoplasias de bovinos, realizados por RAMOS et al., (2008), LUCENA et al., (2011) e CARVALHO (2012), observaram-se frequências de $2 \%, 1 \%$ e $1,4 \%$ de neoplasias do SN em relação ao total de neoplasias diagnosticadas, respectivamente, nos laboratórios de patologia das Universidades de Pelotas (UFPel) e Santa Maria (UFSM), no estado do Rio Grande do Sul e na Universidade de Campina Grande, Campus de Patos no estado Paraíba.

O objetivo deste trabalho é descrever os achados clínicos e patológicos de um caso de meningioma fibroblástico em bovino, atendido no Hospital Veterinário da UFCG, Patos, Paraíba.

Um bovino macho, de dois anos de idade, mestiço, apresentava apatia e apetite diminuído. No exame clínico, depressão, bruxismo, flacidez da língua ao tracioná-la, trismo e secreção nasal mucopurulenta foram observados. $\mathrm{O}$ animal não conseguia apreender o alimento e não bebia água, evoluindo em seis dias para relaxamento de mandíbula, salivação intensa e morte.

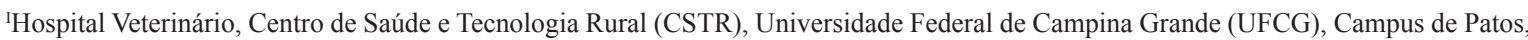
Av. Universitária, S/N, Santa Cecília, 58700-970, Patos, PB, Brasil. E-mail: fabriciokleber@hotmail.com. *Autor para correspondência. IIMédico Veterinário Autônomo, Aracajú, SE, Brasil.

IIILaboratório de Patologia Veterinária, Departamento de Patologia, Universidade Federal de Santa Maria (UFSM), Santa Maria, RS, Brasil. Recebido 15.05.13 Aprovado 26.11.13 Devolvido pelo autor 30.01.14 CR-2013-0675.R3
} 
$\mathrm{Na}$ necropsia, o encéfalo apresentava assimetria dos hemisférios cerebrais, devido ao aumento de volume da região do córtex frontal direito, com área de hemorragia focalmente extensa nas leptomeninges e achatamento das circunvoluções (Figura 1A). A massa tumoral apresentava-se friável e amarelada, medindo aproximadamente $7 \times 3,5 \mathrm{~cm}$ de extensão (Figura 1B), localizava-se no lobo frontal direito e se estendia aos ventrículos lateral direito e terceiro ventrículo, comprimindo o parênquima adjacente, afetando o núcleo caudado direito, o fórnix e o trato olfatório direito (Figura 1C).

Microscopicamente, o neoplasma era formado por células predominantemente arredondadas a ovaladas, algumas vezes alongadas, lembrando fibroblastos ou de formato estrelado (Figura 2A). Apresentavam citoplasma escasso, núcleo arredondado ou alongado, nucléolo único ou raramente múltiplo e cromatina finamente dispersa. Essas células neoplásicas estavam aderidas à dura-máter (Figura 2B), apresentavam acentuado pleomorfismo e arranjavam-se em feixes celulares ou grupos celulares, formando ninhos. O neoplasma era bem vascularizado, com proliferação de células neoplásicas ao redor de vasos, às vezes formando camada densa eosinofílica ou pseudorosetas perivasculares (Figura 2C). Para confirmação do diagnóstico, foi realizada a técnica de imunohistoquímica (IHQ), utilizando-se os anticorpos (Acs) primários: anti-pancitoqueratina bovina (1:2.000; Dako, Z0622), anti-vimentina (1:100; Dako, M0725), antiproteína ácida fibrilar glial (GFAP; 1:10.000, Dako, Z0334) e anti-enolase neuro-específica (pré-diluído, Abcam, ab15488). O Ac secundário biotinilado e o complexo estreptavidina-peroxidase (Dako, K0690) foram incubados consecutivamente a $25^{\circ} \mathrm{C}$ por $35 \mathrm{~min}$ e marcados com diaminobenzidina (DAB; Dako, K3468). A contra-coloração foi com hematoxilina de Harris.

Como controle positivo do GFAP e NSE, utilizou-se seção de cérebro de bovino sem alterações, além de pâncreas canino (positivo para NSE nas ilhotas de Langerhans, conforme recomendações do fabricante). Como controles negativos, foram utilizadas secções do mesmo caso incubadas com o diluente de Ac.

Houve marcação positiva para vimentina (Figura 2D) e negativa para citoqueratina, GFAP e

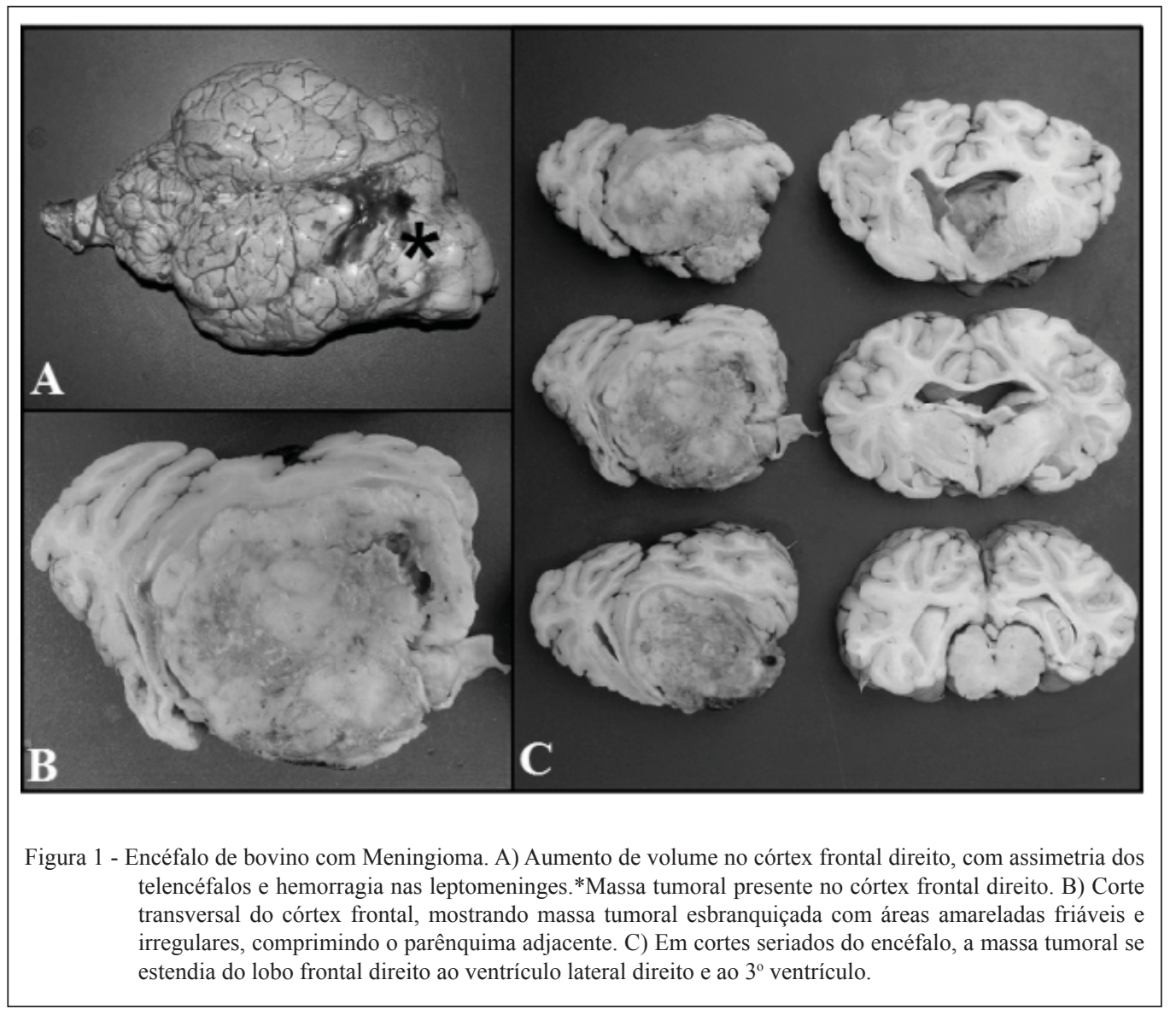

Ciência Rural, v.44, n.4, abr, 2014. 
NSE. O diagnóstico de meningioma fibroblástico foi realizado pelas características histológicas semelhantes às observadas por JOSEPHSON \& LITTLE (1990), e confirmado pela IHQ, pois a vimentina é expressa em todos os subtipos histológicos de meningiomas. A utilização de outros marcadores (E-caderina e CD34) tem sido proposta para meningiomas em cães e gatos (RAMOS-VARA et al., 2010), porém não há estudos em bovinos que confirmem a utilidade desses marcadores em meningiomas nessa espécie. Neoplasmas que ocorrem nas cavidades ventriculares, tais como, carcinoma de plexo coroide e ependimoma, além de outros tumores SNC, como astrocitoma, oligodendroglioma, meduloblastoma devem ser incluídos no diagnóstico diferencial (KOESTNER \& HIGGINS, 2002).

As neoplasias primárias do SNC são consideradas raras no Brasil, constituindo apenas $0,9 \%$ no semiárido nordestino (GALIZA et al., 2010) e $0,33 \%$ na região sul (SANCHES et al., 2000) das doenças do SNC de bovinos. Em estudo retrospectivo de tumores, realizados em ruminantes e equídeos no semiárido do Nordeste brasileiro, a espécie bovina foi a segunda mais afetada por neoplasias, principalmente associada à ocorrência de carcinoma de células escamosas na pele e globo ocular, ficando atrás apenas dos equídeos (CARVALHO, 2012).

Segundo SUMMERS et al. (1995), os sinais clínicos apresentados pelo animal podem ser associados à localização e velocidade de crescimento do tumor, como também devido à compressão cerebral pela massa tumoral. Sinais clínicos como depressão, paresia ou paralisia facial e perda da resposta de ameaça são predominantes em bovinos acometidos por tumor cerebral (SMITH, 2002). As principais doenças do SN diagnosticadas em bovinos no semiárido nordestino são raiva $(48,7 \%)$, abscessos cerebrais $(7,2 \%)$, febre catarral maligna $(6,3 \%)$ e botulismo (6,3\%). Entretanto, outras doenças que ocorrem esporadicamente, como a meningoencefalite por Herpes vírus bovino tipo 5, que podem apresentar sinais clínicos semelhantes aos observados neste caso, devem ser incluídas no diagnóstico diferencial das neoplasias primárias do SNC (GALIZA et al., 2010).

Estudos que descrevem neoplasmas em animais de produção são de grande relevância, uma vez que são poucos os relatos na literatura. Os neoplasmas do SNC são importantes no diagnóstico diferencial de doenças neurológicas infecciosas, como raiva e doenças tóxicas (plantas e metais pesados).

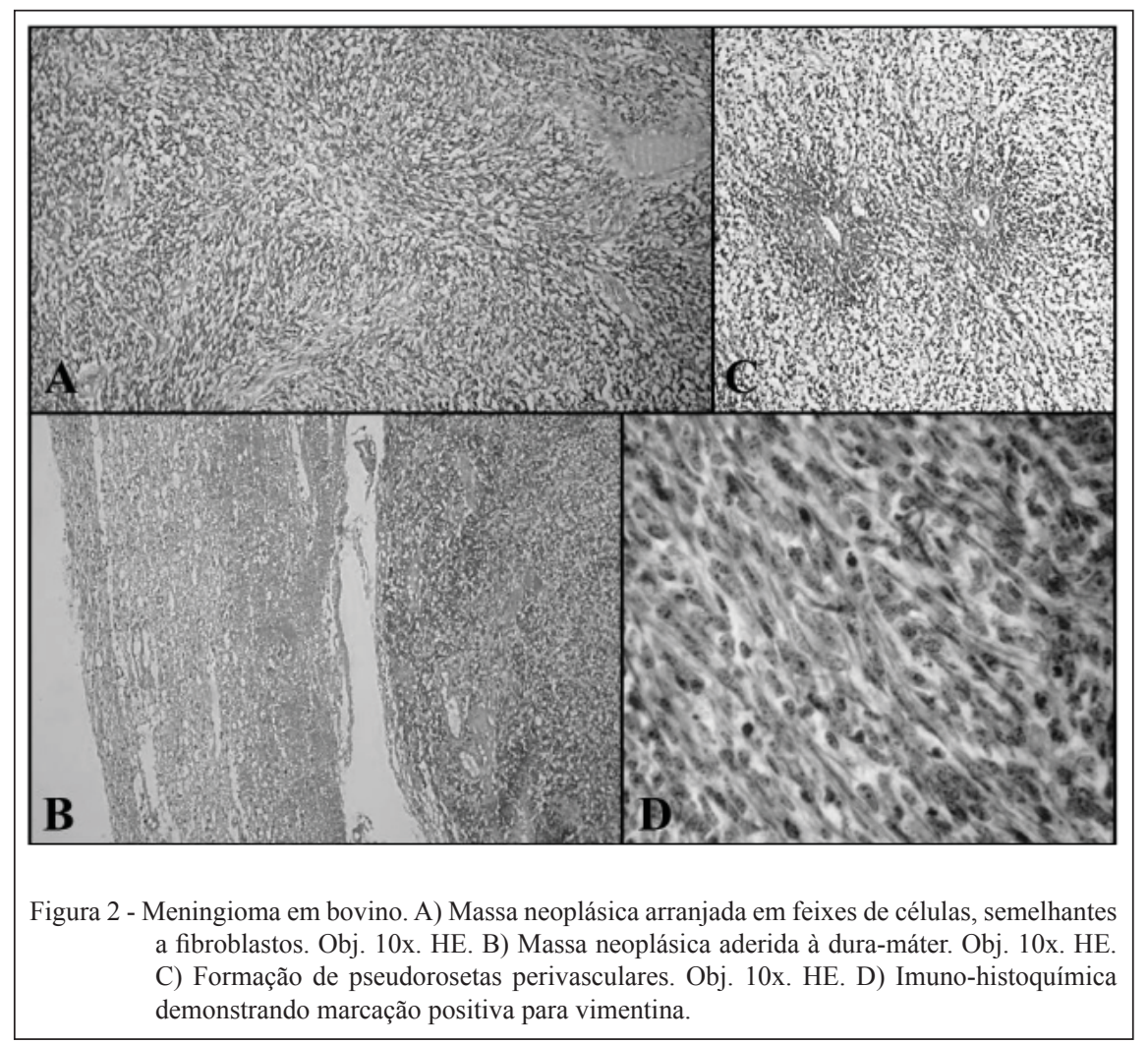

Ciência Rural, v.44, n.4, abr, 2014. 


\section{REFERÊNCIAS}

CARVALHO, F.K.L. Neoplasias em ruminantes e equídeos diagnosticadas no semiárido da Paraíba. 2012. 48f Dissertação (Mestrado em Medicina Veterinária) - Centro de Saúde e Tecnologia Rural, Universidade Federal de Campina Grande, Patos, PB.

GALIZA, G.J.N. et al. Doenças do sistema nervoso de bovinos no semiárido nordestino. Pesquisa Veterinária Brasileira, v.30, n.3, p.267-276, 2010. Disponível em: <http://www.scielo.br/scielo. php?pid $=$ S0100-736X2010000300014\&script $=$ sci abstract\&tlng $=p t>$. Acesso em: 30 set. 2011. doi: 10.1590/S0100-736X2010000300014.

JOSEPHSON, G.K.A.; LITTLE, P.B. Four bovine meningeal tumors. Can Vet J, v.31, p.700-703, 1990. Disponivel em: $<$ http://www.ncbi.nlm.nih.gov/pmc/articles/PMC1480858/pdf/ canvetj00083-0034.pdf>. Acesso em: 04 jul. 2013.

LUCENA, R.B. etal.ARetrospectiveStudy of586TumoursinBrazilianCattle. Journal Comparative Pathology, v.145, p.20-24, 2011. Disponível em: $<$ http://www.sciencedirect.com/science/article/pii/S0021997510003324\#>. Acesso em: 23 mar. 2012. doi: 10.1016/j.jcpa.2010.11.002.

KOESTNER, A.; HIGGINS, R.J. Tumors of the nervous system. In: MEUTEN D.J. Tumors in domestic animals. 4.ed. Ames: Iowa State, 2002. p.697-738.
RAMOS, A.T. et al. Tumores em animais de produção: aspectos comparativos. Ciência Rural, v.38, n.1, p.148-154, 2008. Disponível em: <http://www.scielo.br/scielo.php?script=sci_artte xt\&pid=S0103-84782008000100024>. Acesso em: 13 mar. 2011. doi: $10.1590 / \mathrm{S} 0103-84782008000100024$

RAMOS-VARA, J.A et al. Immunohistochemical detection of CD34, E-cadherin, Claudin-1, glucose transporter 1, Laminin, and protein gene product 9.5 in 28 canine and 8 feline meningiomas. Veterinary Pathology, v.47, n.4, p.725-737, 2010. Disponível em: <http://vet.sagepub.com/ content/47/4/725.full.pdf + html $>$. Acesso em: 04 jul. 2013. doi: $10.1177 / 0300985810364528$.

SANCHES, A.W.D. et al. Doenças do sistema nervoso central em bovinos no sul do Brasil. Pesquisa Veterinária Brasileira, v.20, n.3, p.113-118, 2000. Disponível em: <http:// www.scielo.br/scielo.php? script $=$ sci_arttext\&pid $=\mathrm{S} 0100-$ 736X2000000300005>. Acesso em: 10 ago. 2012. doi: 10.1590/ S0100-736X2000000300005.

SMITH, B.P. Large animal internal medicine. 3.ed. St Louis: Mosby, 2002. 2112p.

SUMMERS, B.A. et al. Veterinary neuropathology. Baltimore: Mosby, 1995. 527p 